\title{
Potential Implications of Medicinal Plant Production in Controlled Environments: The case of Feverfew (Tanacetum parthenium)
}

\author{
Jorge M. Fonseca ${ }^{1}$ \\ The University of Arizona, Yuma Agricultural Center, Yuma, AZ 85364-9623 \\ James W. Rushing \\ Clemson University,. Coastal Research and Education Center, Charleston, SC 29414-5332 \\ Nihal C. Rajapakse \\ Clemson University, Department of Horticulture, Clemson, SC 29634-037 \\ Ronald L. Thomas \\ Clemson University, Department of Packaging Sciences, Clemson, SC 29634-0375 \\ Melissa B. Riley \\ Clemson University, Department of Plant Pathology and Physiology, Clemson, SC 29634-0375
}

Additional index words. abscisic acid, light, parthenolide, phenolics, water stress

\begin{abstract}
Summary. The purpose of this review is to promote a discussion about the potential implications of herb production in controlled environments, focusing on our recent works conducted with feverfew. Research suggests that the content of secondary metabolites in medicinal plants fluctuates with changing environmental conditions. Our studies with feverfew (Tanacetum parthenium [L.] Schultz-Bip., Asteraceae) lend support to this hypothesis. Feverfew plants exposed to different water and light conditions immediately before harvest exhibited changes in content of some secondary metabolites. The highest yield of parthenolide (PRT) was in plants that received reduced-water regimes. Phenolics concentration however, was higher in plants receiving daily watering. Light immediately before harvest enhanced accumulation of PRT, but reduced the phenolic content. Notably, PRT decreased at night whereas total phenolics decreased during the photoperiod and increased at night. PRT also increased with increased plant spacing. UV light supplementation increased PRT only in plants that had undergone water stress, whereas phenolics increased when UV was applied to continuosly watered plants. Clearly, production of medicinal plants under greenhouse conditions is a promising method for controlling levels of phytochemicals through manipulation of light and water as discussed here, and possibly other environmental factors such as temperature and daylength. However, better understanding of how the environment alter secondary metabolite levels is needed as it was revealed that manipulating the environment to favor increased accumulation of one group of phytochemicals could result in a decline of other key metabolites.
\end{abstract}

\section{NEED FOR CONSISTENT HERBAL QUALITY}

The phytochemical composition of herbal products is highly variable (Bauer and Tittel, 1996). A number of factors can affect the quality of medicinal products including the seed source, temperature, light exposure, water availability, fertility, period, time and method of collection, drying, packing, storage and transportation of raw material, age and part of the plant collected, the method of extraction and contamination with microorganisms (Calixto, 2000). Specific reports on production and postharvest handling practices to maximize quality of individual medicinal plants and herbs are needed.

Feverfew (Tanacetum parthenium L. Schulz-Bip.), is a perennial Compositae plant regarded as an effective prophylactic treatment of migraine, rheumatoid arthritis and menstrual cramps (Grauds 1995). Parthenolide (PRT), a sesquiterpene lactone (Groenewegen and Heptinstall, 1992) associated with the

South Carolina Agricultural Experiment Station technical contribution 5164 .

${ }^{1}$ Corresponding author; e-mail jfonseca@ag. arizona.edu. medicinal effects of feverfew, was found to vary substantially in commercial products available in the U.S. market (Awang et al., 1991). Smith and Burford (1992) surveyed feverfew tablets and capsules and observed that PRT concentration usually was below the amount reported in the product labels. They suggested that a number of pre-harvest and postharvest factors could cause the unexpected decrease in quality.

Reduced variability in herbal quality might be obtained through breeding techniques but reports on the development of medicinal plant cultivars with enhanced bioactivity are lacking (Canter et al., 2005). With some exceptions, such as Cannabis sp. (Gilmore and Peakall, 2003) and Mentha sp. (Veronese et al., 2001), medicinal plants have not been addressed in molecular marker or bioengineering studies. One obstacle to both conventional and molecular approaches in developing a new variety is the high cost. The lack or reliable bioassays also play an important role in developing new varieties. In addition, environmental factors influence accumulation of key compounds. When clones are cultivated the interaction between the environment and the clones has been significant (Oksanen, 2003; Wamatu et al., 2003). Given this scenario it is imperative to study how and to what magnitude environmental factors affect phytocompounds with medicinal activity. Greenhouse production, due to a better control of the environment, appears to be an ideal system to produce plants with consistently high levels of desired phytochemicals. Published reports on how environmental factors affect compounds of therapeutic interest are scarce, but recent work has shown that we can manipulate production conditions to enhance the levels of metabolites. This review discusses the possible benefits, and related implications, of controlled environments for the production of high quality herbals, using our recent data with feverfew Tanacetum parthenium (L.) SchultzBip., (feverfew, Asteraceae) as a model.

\section{OPPORTUNITY FOR HERBAL PRODUCTION IN CONTROLLED ENVIRONMENTS}

A number of medicinal plants respond to environmental manipulation. For example controlled environments have been useful to shorten the stratitification period and increase the germination rate and seed viability thus, enabling the germination of seeds of Panax quinquefolium (American ginseng) all year round (Li et al., 2000). 


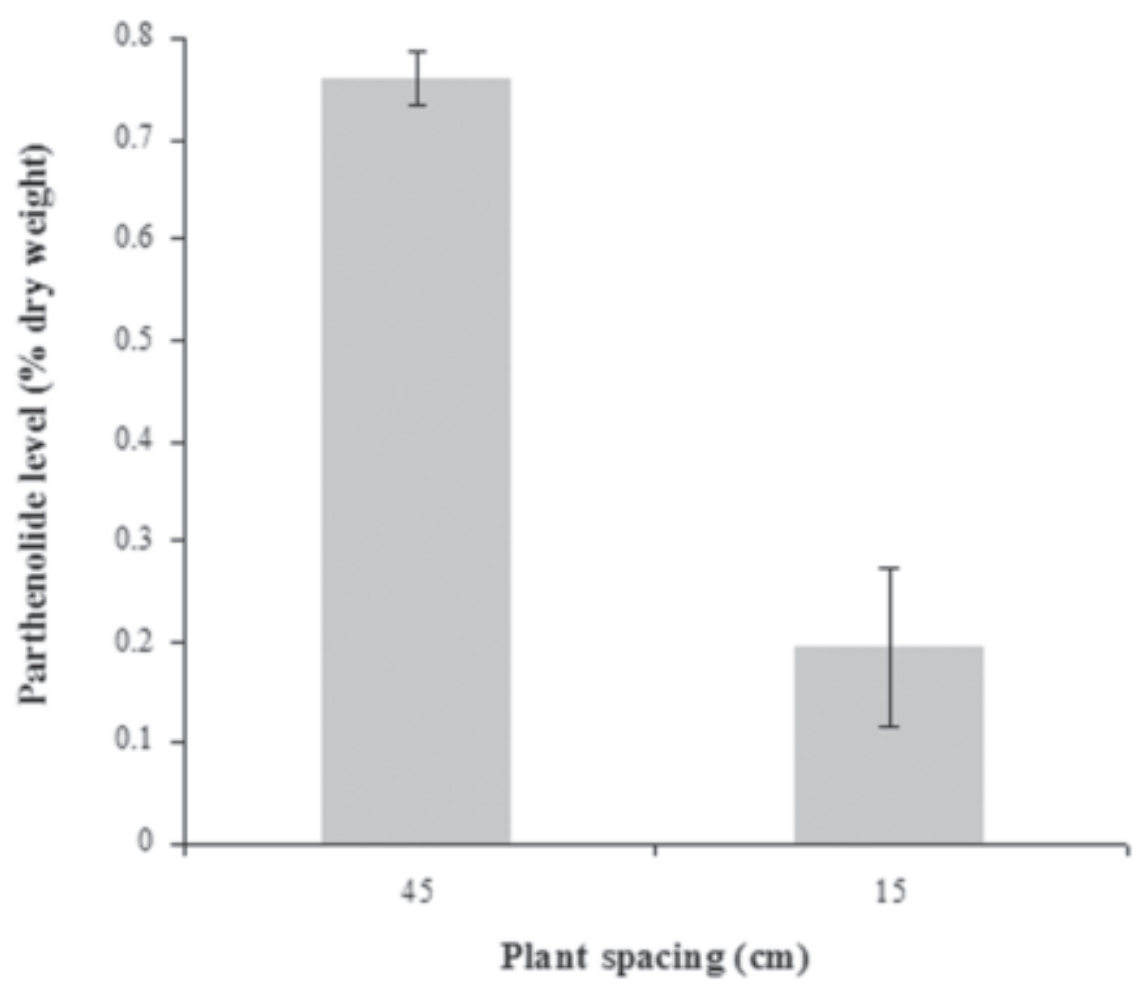

Fig. 1. Influence of plant spacing during the last week before harvest on parthenolide content in feverfew. Plants were grown in greenhouse for 5 months at $15 \mathrm{~cm}$ spacing until a week before harvest (March) A significant difference was found between the two treatments $\left(\mathrm{LSD}_{0.05}=0.211\right)$. Values are the average of eight samples. Error bars indicate SE.

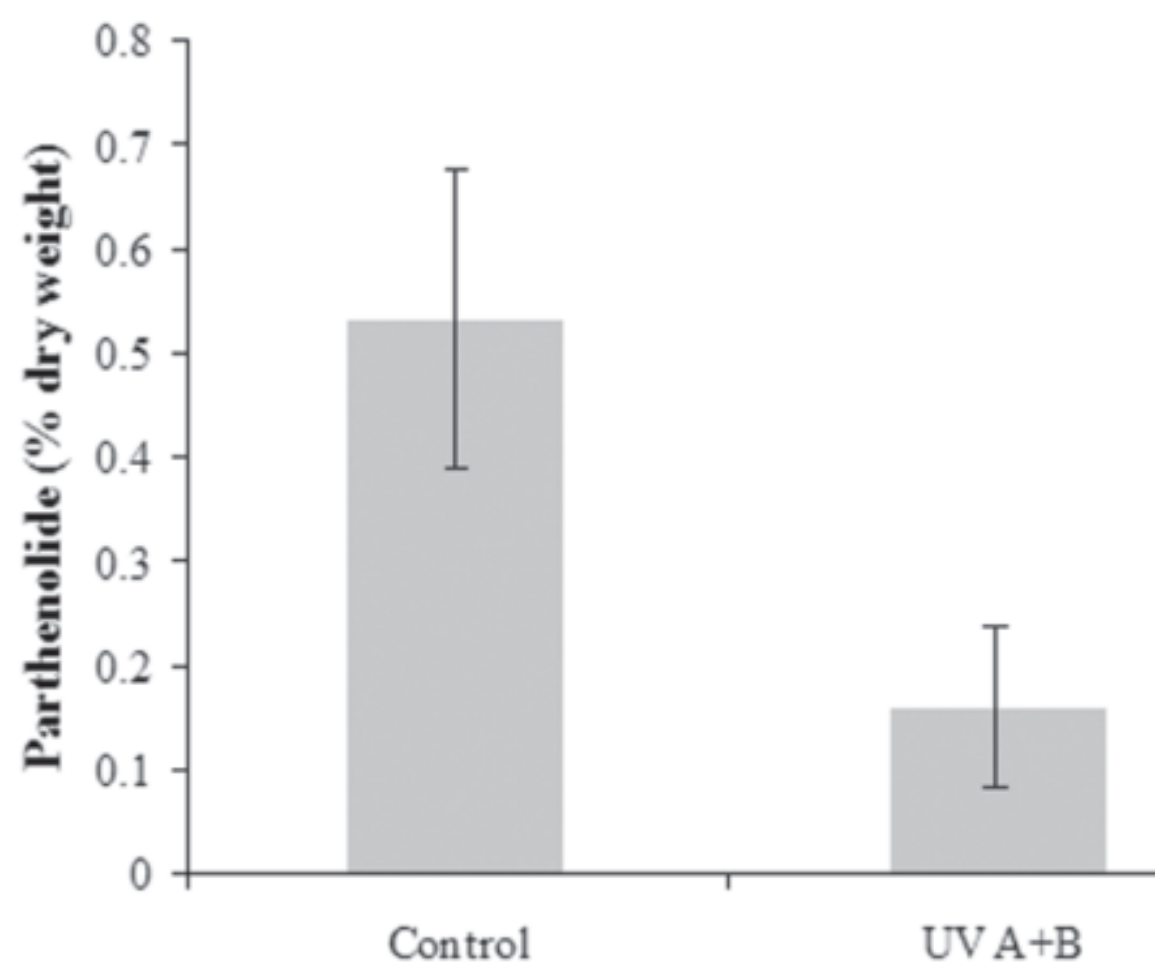

Fig. 2. Effect of $U V A+B\left(3.5+3.5 \mu \mathrm{W} \cdot \mathrm{m}^{-2}\right)$ applied continuously for $12 \mathrm{~h}$ before harvest on the parthenolide accumulation in feverfew. Experiment was conducted during February and March. Values are the average of eight samples. A significant difference was found between the two treatments $\left(\mathrm{LSD}_{0.05}\right.$ $=0.248)$. Error bars indicate SE
Environmental conditions could be modified in greenhouse production to maximize the accumulation of key compounds. Subjecting plants to regulated stress in particular can result in changes in levels of secondary metabolites, some of which may be of medicinal interest. The accumulation of these metabolites is driven by the availability of excess carbon. When growth is reduced due to stress, more carbon becomes available for secondary metabolism thus, inducing the production of some phytochemicals (Tuomi et al., 1984). It is known that in various plants environmental stress increases the accumulation of phenolics (Keinanen, 1999).

Plants grown in greenhouses can be easily exposed to changing light irradiance, which is one factor expected to modify the chemical composition of plants. Visible light alters the carbon partition in plants and induces changes in levels of secondary metabolites (Alba et al., 2000). Exposure to high visible radiation may increase the xanthophyll cycle activity and subsequent production of various secondary metabolites (Thiele et al., 1996). Under low lightintensities, ABAincreases, which regulates some processes in secondary metabolism (Nan et al., 2002).

The effect of visible light on plant metabolism can be observed by harvesting at different times of day, by artificially extending the photoperiod, or by supplementing light during the photoperiod. Secondary metabolites are prone to diurnal fluctuation (Veit et al., 1996), a response likely due to the effects of light intensity (Stoker et al., 1998; Kolb et al., 2001), UV light incidence (Langenheim, 1994; Kolb et al., 2001) or both (Middleton and Teramura, 1994; Adamse and Britz, 1992). Ultraviolet-B radiation can additionally affect anatomical and morphological characteristics of plants (Teramura and Sullivan, 1994). UV light has been reported to both increase (Vogt et al., 1999) and decrease (Kolb etal., 2001) phenolics content of plants. Visible light intensity appears to be an important factor affecting UV light response in plants (Middleton and Teramura, 1994; Adamse and Britz, 1992). In woad (Isatis tinctoria) the indigo yields increased significantly with increasing UV light only when the photosynthetically active radiation also was at high levels (Stoker et al., 1998). For production in controlled environment systems the effect of the ratio visible light:UV light needs to be taken into account, since certain types of greenhouse facilities filter out UV light rays.

Water stress is another factor that can potentially alter concentration of key compounds in medicinal plants. Plants under water stress normally show increased accumulation of ABA (Kobashi et al., 2000; Jensen et al., 1996) which triggers changes in content of other secondary metabolites such as phenolics, tannins, proline, polyamines, and terpenoid compounds (ChangHung, 1999; Horner, 1990; Lazcano-Ferrat and Lovatt, 1999).

\section{FEVERFEW QUALITY AS AFFECTED BY THE ENVIRONMENT}

Effect of light availability at harvest. We recently confirmed that PRT content in fever- 


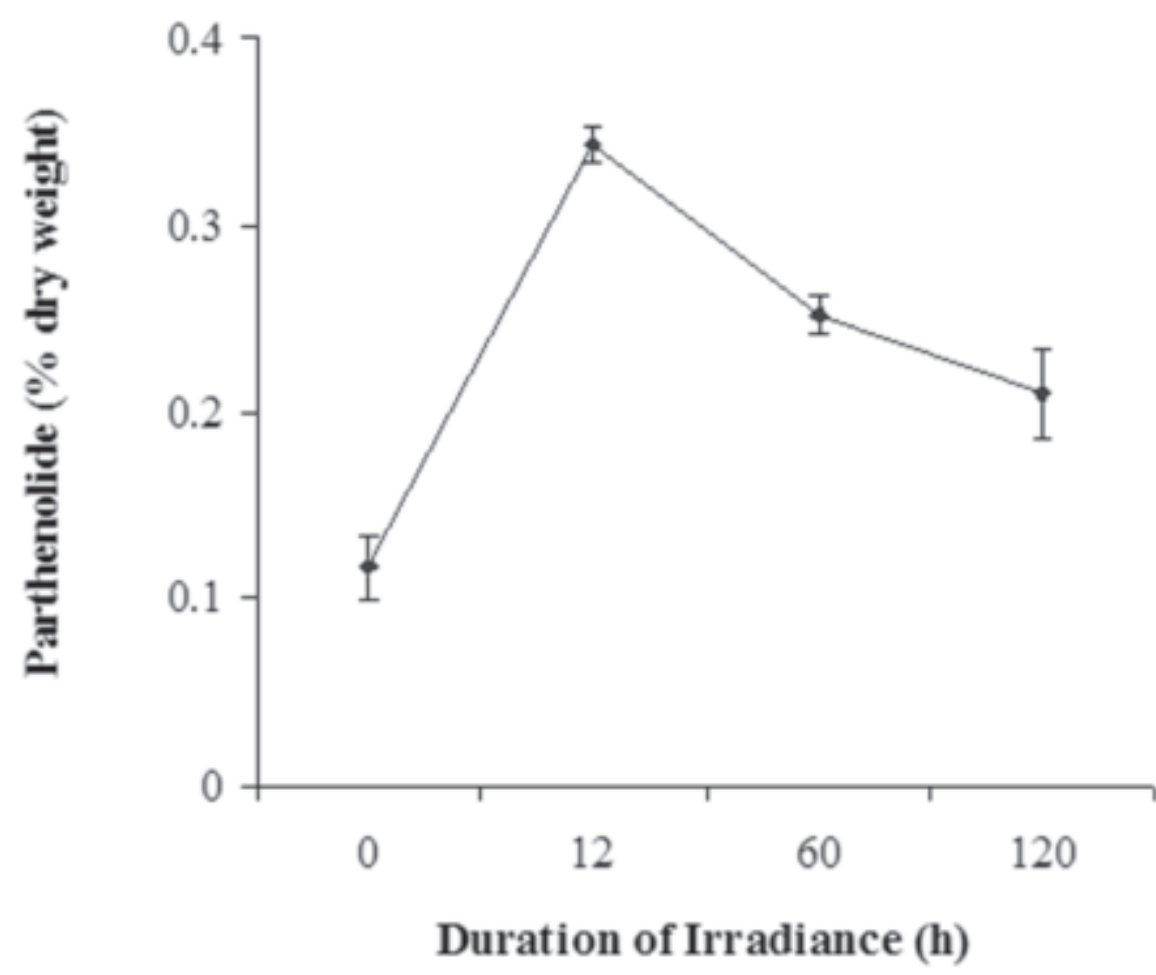

Fig. 3. Effect of UVA+B $\left(3.5+3.5 \mu \mathrm{W} \cdot \mathrm{m}^{-2}\right)$ light exposure (intervals of $12 \mathrm{~h}$ daily) on the content of parthenolide in feverfew plants previously submitted to water stress-recovery cycles for 3 weeks. Harvest of two batches was conducted during the month of September. A significant difference was found among treatments $\left(\mathrm{LSD}_{0.05}=0.088\right)$. Error bars indicate SE.

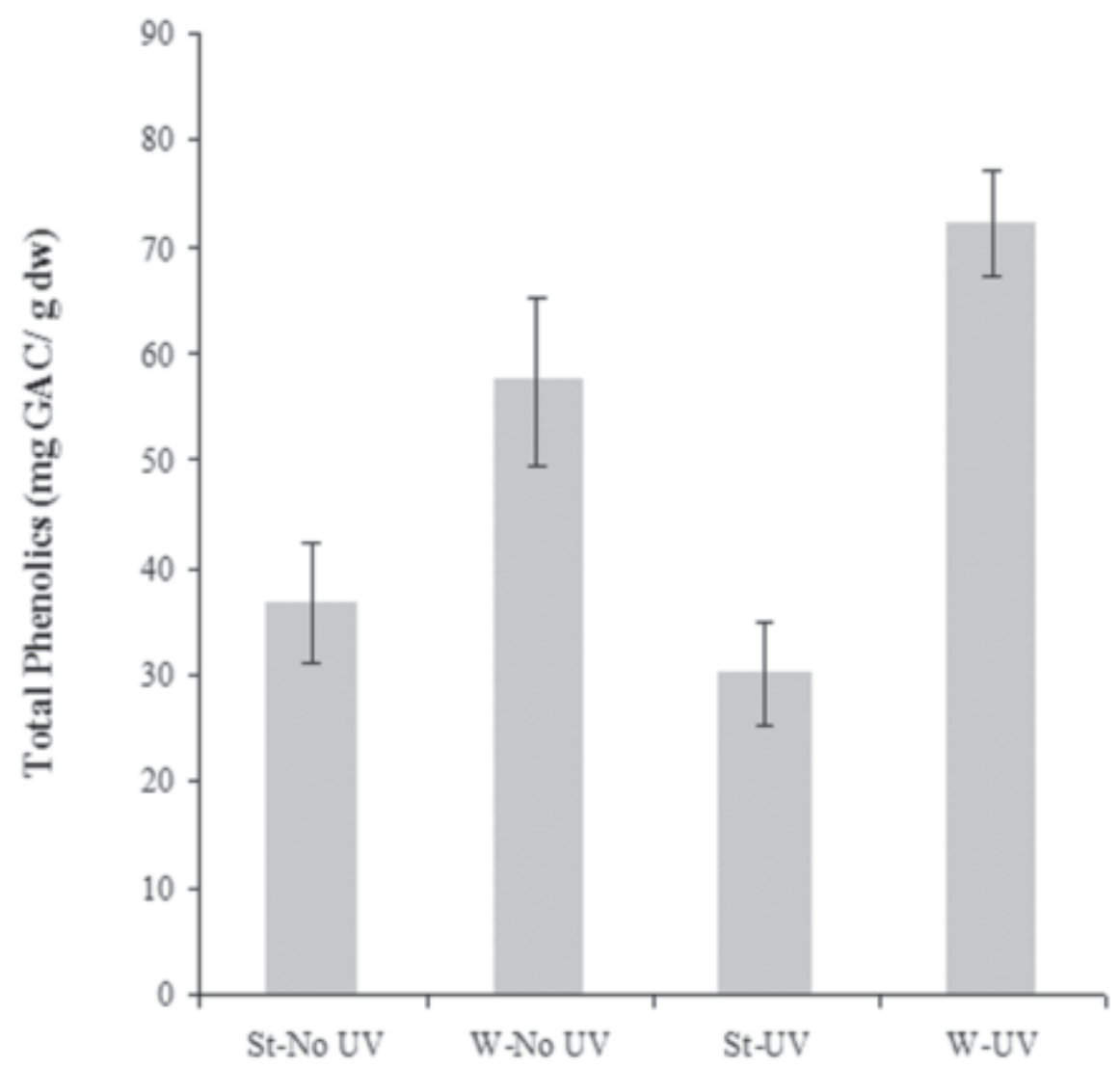

Fig. 4. The effect of water stress and UV A+B $\left(3.5+3.5 \mu \mathrm{W} \cdot \mathrm{m}^{-2}\right)$ light on the content of total phenolics in feverfew harvested during the months of August and September. $\mathrm{St}=$ the plants subjected to water stress; $\mathrm{W}=$ the plants that were watered daily; $\mathrm{UV}=$ the plants that were subjected to UV A+B light. Values are the means of nine samples. Interaction of UV treatment and water stress effect was significant $(p \leq 0.05)$. LSD for comparison of simple effects was 14.98. Error bars indicate SE. few is affected when plants are exposed to different environmental conditions. The effect of light was evaluated by harvesting plants at different times of the day. The lowest amount of PRT was observed in plants harvested at night and the maximum level was observed during late afternoon (Fonseca et al., 2005a). Moreover, plants exposed to artificial light during night hours had increased PRT (Fonseca et al., 2003). The critical effect of sunlight on PRT concentration was also revealed when we increased the plant spacing from 15 to $45 \mathrm{~cm}, 1$ week before harvest (Fig.1). The increased in light availability, as a result of the reduction in plant density, produced a 3 -fold increase in PRT. Further research is needed to determine conditions that maximize yield per cultivated area.

In addition to PRT, certain phenolics may contribute to the medicinal value of feverfew (Williams et al., 1995; Williams et al., 1999). In contrast to the pattern observed with PRT, phenolics in feverfew were found to increase at night and decrease during daylight (Fonseca et al., 2003). This trend observed with phenolic levels in feverfew has been observed in other plants (Burns et al., 2002; Veit et al., 1996).

Abscisic acid (ABA) is involved in the response of plants to stress, thus, it plays an important role in the dynamics of secondary metabolism. UV light leads to rapid closure of the stomata due to increased ethylene production within tissues and subsequent increase of ABA (Rajagopal et al. 1987, Soheila and Mackerness 2000). Exogenous application of ethylene increases ABA and alkaloids content (Buzuk et al. 1989). In leaves, ABA may be higher in plants exposed to either very low (Nan et al. 2002) or very high photosyntetically active radiation (Thiele et al. 1996). In feverfew, ABA levels changed with the same factors that affected PRT concentration. ABA was higher in water stressed plants and during late morning. Shading plants during afternoon resulted in increased levels of ABA (Fonseca et al., 2005a). The same ABA diurnal pattern, having a peak at late morning, was reported previously in peach trees (Correia et al., 1997).

The rapid response of secondary metabolism to light and dark treatments is connected to shifts in enzymatic activity. Changes in light conditions have been reported to cause rapid changes in activity of certain enzymes (Matamoros et al., 1999) and photoreceptors (Halliday et al., 1999). The role of phenylalanine may shift from initiating protein formation to enhancing phenolic synthesis upon changes in light conditions (Tuomi et al., 1984). The key enzymes for the synthesis of ABA, 9-cis-epoxycarotenoid dioxygenase and zeaxanthin epoxidase (Seo and Koshiba, 2002) have shown diurnal fluctuation (Audran et al., 1998; Thompson et al., 2000).

Effect of water stress. Manipulating water availability in the production system can result in diverse phytochemical profiles. Water stress increases the production of jasmonic acid and ABA, which results in stomata closure (Wasstenack and Parthier, 1997), and accumulation of sesquiterpene (Singh et al., 1998) and tannins (Horner, 1990). In our studies plants 
under water stress had higher PRT levels than plants receiving water daily (Fonseca et al., 2005a). Unlike the pattern observed with PRT, plants growing under reduced-water conditions had lower phenolic content than plants that received continuous irrigation (Fonseca et al., 2003). An important aspect to consider when inducing plants to regulated water stress is the potential synergistic or antagonistic effect of multiple stress-producing conditions. As described above, UV light may or may not enhance secondary metabolites depending on a second factor, notably total photosynthetic active radiation (Adamse and Britz, 1992; Middleton and Teramura, 1994; Stoker et al., 1998). We found that PRT declined in turgid plants exposed to UV A+B (Fig. 2); however, increased PRT was observed when UV A+B was supplemented to plants that had been subjected to water stress. The increase was shorter when the exposure to UV irradiation surpassed 12 hours (Fig. 3). Contrary to this pattern, the content of phenolics increased with UV A+B light only in plants that had not been subjected to water stress (Fig. 4). Clearly, any benefit of a water stress condition in enhancing metabolites may be accompanied with undesired results, e.g. a reduction of total mass per area. However, it might be possible to develop controlled stress programs that can increase metabolites concentration without substantially affecting yield. Such a production system would be more easily developed in greenhouse settings, than in open fields.

\section{CONCLUSION}

Medicinal plants are inherently variable in content of secondary metabolites. It is desirable to develop systems that can assure production of plants with high levels of medicinally active compounds. Our studies with subjecting feverfew to different water and light conditions revealed that environmental factors affect herbal quality. Undoubtedly, other factors may also have a dramatic interaction with secondary metabolites. Hendriks et al. (1997) observed that vegetative plants accumulated higher PRT levels than reproductive plants that are normally in bloom during the summer. Similarly, we consistently obtained higher PRT levels in our greenhouse experiments with plants grown during the winter (Fonseca et al., 2005b). Daylength could be another factor to consider when growing plants in a greenhouse.

It is critical to know the effect of the environment on individual phytochemicals. In general, we can assume that phytochemicals are degraded during postharvest storage, which stresses the significance of enhancing levels of key compounds during production. Rushing et al. (2004), showed that drying feverfew plants at temperatures higher than $60{ }^{\circ} \mathrm{C}$ decrease PRT. We observed that PRT levels decreased $30 \%$ after eleven months of storage (Fonseca et al., 2005c). Similarly, a marked decline in PRT concentration during post-processing storage was reported by Heptinstall et al. (1992).

The content of compounds with potential medicinal activity in plants can be affected dissimilarly by environmental factors. If a medicinal plant is grown in a controlled environment system for improved phytochemical production, it will inherently involve a decision of which metabolite to target, knowing that such a decision will potentially result in a trade off, e.g., decreased levels of other key phytochemicals. Greenhouse production of medicinal plants is, from the technical perspective, a promising approach for obtaining high quality products but we must first identify what the bioactive phytochemicals are, then determine the relevant metabolic pathways that can be influenced by environmental manipulation.

\section{Literature Cited}

Adamse, P. and S. J. Britz. 1992. Amelioration of UV-B damage under high irradiance. I: role of photosynthesis. Photochem. Photobiol. 56:645-650

Alba, R., M. Cordonnier-Pratt and L.H. Pratt. 2000. Fruit-localized phytochromes regulate lycopene accumulation independently of ethylene production in tomato. Plant Physiol. 123:363-370.

Audran, C., C. Borel, A. Frey, B. Sotta, C. Meyer, T. Simonneau, and A. Marion-Poll 1998. Expression studies of the zeaxanthin epoxidase gene in Nicotiana. Plumbaginifolia. Plant Physiol. 118:1021-1028.

Awang D., B. Dawson, and D. Kindack. 1991. Parthenolide content of feverfew (Tanacetum parthenium) assessed by HPLC and H-NMR spectroscopy. J. Natural Prod. 54:1516-1521.

Bauer, R and G. Tittel. 1996. Quality assessment of herbal preparations as a precondition of pharmacological and clinical studies. Phytomedicine 2:193-198.

Burns, A.E., R.M. Gleadow, and I.E. Woodrow. 2002. Light alters the allocation of nitrogen to cyanogenic glycosides in Eucaliptus cladocalyx. Oecologia 133:288-294.

Buzuk, G.N., M.Y. Lovkov, and N.S. Sabirova 1989. On the role of stress factors abscisic acid and ethylene in the biosynthesis of alkaloids in plants. Rastitel'nye Resursy 25:155-160.

Calixto, J.B. 2000. Efficacy, safety, quality control, marketing and regulatory guidelines for herbal medicines (phytotherapeutic agents). Brazilian J. Medical Biol. Res. 33:179-189.

Canter, H.C., H. Thomas, and E. Ernst. 2005. Bringing medicinal plants into cultivation: Opportunities and challenges for biotechnology. TREND in Biotechnol. 23:180-185.

Chang-Hung, C. 1999. Roles of allelopathy in plant biodiversity and sustainable agriculture. Crit. Rev. Plant Sci. 18:609-636.

Correia, M.J., M.L. Rodrigues, M.I. Ferreira, and J. S. Pereira. 1997. Diurnal change in the relationship between stomatal condutance and abscisic acid in the xylem sap of field-grown peach trees. J. Exp. Bot. 48:1727-1736.

Fonseca, J.M. 2003. Environmental and post-production factors affecting content and stability of parthenolide in feverfew. $\mathrm{PhD}$ diss. Clemson Univ., Clemson, S.C.

Fonseca, J.M., J.W. Rushing, N.C. Rajapakse, R.L. Thomas, and M.B. Riley. 2005a. Parthenolide and abscisic acid synthesis in feverfew are associated but environmental factors affect them dissimilarly. J. Plant Physiol. 162:485-494.

Fonseca, J.M., J.W. Rushing, R.L. Thomas, M.B. Riley and N.C. Rajapakse. 2005b. Influence of particle size on extraction yield and quantification of parthenolide in feverfew (Tanacetum parthenium). Acta Hort. (n press).

Fonseca, J.M., J.W. Rushing, R.L. Thomas, M.B.
Riley and N.C. Rajapakse. 2005c. Post-production stability of parthenolide in feverfew (Tanacetum parthenium). J. Herbs Spices Med. Plants (in press).

Gilmore, S. and R. Peakall. 2003. Isolation of microsatellite markers in Cannabis sativa $\mathrm{L}$. (marijuana) in fibre crops varieties. Mol. Ecol. Notes 3:105-107.

Grauds, C. 1995. Treating migraine and arthritis with feverfew. Pharm. Times. 61:32-34.

Groenewegen, W.A. and S. Heptinstall. 1992. Progress in the medicinal chemistry of the herb, feverfew. Prog. Med. Chem. 29:217-238.

Halliday, K.J., C. Bolle, N.H. Chua, and G.C. Whitelam. 1999. Overexpression of rice phytochrome A partially complements phytochrome B deficiency of Arabidopsis. Planta 207:401-409.

Hendriks, K., Y.Anderson-Wildeboer, G. Engels, R. Gos, and H.J. Woerdenbag. 1997. The content of parthenolide and its yield per plant during the growth of Tanacetum parthenium. Planta Med. 63:356-359.

Heptinstall, S., D.V.C. Awang, B.A. Dawson, D. Kindack, D.W. Knight, and J. May. 1992. Parthenolide content and bioactivity of feverfew (Tanacetum parthenium (L.) Schultz-Bip.). Estimation of commercial and authenticated feverfew products. J. Pharm. Pharmacol. 44:391-395.

Horner, J.D. 1990. Nonlinear effects of water deficits on foliar tannin concentration. Biochem. Syst. Ecol. 18:211-213.

Jensen, A.B., P.K. Busk, M. Figueras, M. Mar-Alba, G. Peracchia, R. Messeguer, A. Goday, and M. Pages. 1996. Drought signal transduction in plants. Plant Growth Regul. 20:105-110.

Keinanen, M. 1999. Trade-offs in phenolic metabolism of silver birch: Effects of fertilization, defoliation, and genotype. Ecology 9:1-27

Kobashi, K., H. Gemma, and S. Iwahori. 2000. Abscisic acid content and sugar metabolism of peaches grown under water stress. J. Amer. Soc. Hort. Sci. 125:425-428.

Kolb, C.A., M. A. Kaser, J. Kpecky, G. Zotz, M. Riederer, and E.E. Pfundel. 2001. Effects of natural intensities of visible and ultraviolet radiation on epidermal ultraviolet screening and photosynthesis in grape leaves. Plant Physiol. 127:863-875.

Langenheim, J.H. 1994. Higher-plant terpenoids- a phytocentric overview of their ecological roles. J. Chem. Ecol. 20:1223-1280.

Lazcano-Ferrat, I. and C.J. Lovatt. 1999. Relationship between relative water content, nitrogen pools, and growth of Phaseolus vulgaris L. and P. acutifolius A. Gray during water deficit. Crop. Sci. 39:467-475.

Li, T.S.C., K.E. Bedford, and P.L. Sholberg. 2000. Improved germination of American ginseng seeds under controlled environmentas. HortTechnology 10:131-135.

Matamoros, M.A., L.M. Baird, P.R. Escuredo, D.A. Dalton, F.R., I. Iturbe-Ormaetxe, M.C. Rubio, J.F. Moran, A.J. Gordon, and M. Becana. 1999. Stress-induced legume root nodule senescence. Plant Physiol. 121:97-111.

Middleton E.M. and A.H. Teramura. 1994. Understanding photosynthesis, pigment and growth responses induced by UV-B and UV-A irradiances. Photochem. Photobiol. 60:38-45.

Nan, R., J.G. Carman, and F.B. Salisbury. 2002. Water stress, $\mathrm{CO}_{2}$ and phtotoperiod influence hormone levels in wheat. J. Plant Physiol. 159:307-312.

Oksanen, E. 2003. Responses of selected birch (Betula pendula Roth). Plant Cell Environ. 26:875-882.

Rajagopal, R., P. Ulvskov, J. Marcussen, J.M Andersen, and S. Allerup. 1987. Hormonal and phenolic changes accompanying and following 
UV-C induced stress in Spathiphyllum leaves. J. Plant Physiol. 130:291-306.

Rushing, J.W., R.L. Hasell, and R.J. Dufault. 2004. Drying temperatures and stage of development at harvest influence active principle in feverfew, Tanacetum parthenium L. Acta Hort. 629:167-173.

Seo, M. and R. Koshiba. 2002. Complex regulation of ABA biosynthesis in plants. TRENDS Plant Sci. 7:41-48.

Singh, G., J. Gavrieli, J.S. Oakey, and W.R. Curtis. 1998. Interaction of methyl jasmonate, wounding and fungal elicitation during sesquiterpene induction in Hyoscyamus muticus in root cultures. Plant Cell Reprod. 17:391-395.

Smith, R.M. and M.D. Burford. 1992. Supercritical fluid extraction and gas chromatographic determination of the sesquiterpene lactone parthenolide in the medicinal herb feverfew (Tanacetum parthenium). J. Chrom. 627:255-261.

Soheila, A. and H. Mackerness. 2000. Plant responses to ultraviolet-B (UV-B: $280-320 \mathrm{~nm}$ ) stress: what are the key regulators? Plant Growth Regul. 32:27-39.

Stoker, K.G., D.T. Cooke, and D.J. Hill. 1998. Influ- ence of light on natural indigo production from woad (Isatis tinctoria). Plant Growth Regul. 25:181-185.

Teramura, A.H. and J. H. Sullivan. 1994. Effects of UV-B radiation on photosynthesis and growth of terrestrial plants. Photosyn. Res. 39:463-473.

Thiele, A., K. Schirwitz, K. Winter, and H. Krause. 1996. Increased xanthophylls cycle activity and reduce D1 protein inactivation related to photoinhibition in two plant systems acclimated to excess light. Plant Sci. 115:237-250.

Thompson, A. J., A.C. Jackson, R.A. Parker, D.R. Morpeth, A. Burbidge, and I.B. Taylor. 2000. Abscisic acid biosynthesis in tomato: regulation of zeaxanthin epoxidase and 9-cis-epoxycarotenoid dioxygenase $m$ RNAs by light/dark cycles, water stress and abscisic acid. Plant Mol. Biol. 42:833-845.

Tuomi, J., P. Niemela, E. Haukioja, S. Siren, and S. Neuvonen. 1984. Nutrient stress: an explanation for plant anti-herbivore responses to defoliation. Oecologia 61:208-210.

Veit, M., W. Bilger, T. Mulhlbauer, W. Brummet, and K. Winter. 1996. Diurnal changes in flavonoids. J. Plant Physiol. 148:478-482.
Veronese, P., X. Li, S. Niu, S. C. Weller, R.A. Bressan, and P. M. Hasegawa. 2001. Bioengineering mint crop improvement. Plant Cell Tissue Organ Cult. 64:133-144.

Vogt, T., M. Igdah, J. Schmidt, V. Wray, M. Nimtz, and D. Strack. 1999. Light-induced betacyanin and flavonol accumulation in bladder cells of Mesembryanthemum crystallinum. Phytochemistry $52: 583-592$.

Wamatu, J.N., E. Thomas, and H.P. Piepho. 2003. Responses of different arabica coffee (Coffea arabica L.) clones to varied environmental conditions. Euphytica 129:175-182.

Wasttenack, C. and B. Parthier. 1997. Jasmonatesignalled plant gene expression. TRENDS Plant Sci. 2:302-307.

Williams, C., J.R.S. Hoult, J.B. Harborne, J. Greenham, and J. Eagles. 1995. A biologically active lipophilic flavonol from Tanacetum parthenium. Phytochemistry 38:267-270

Williams, C.A., J.B. Harborne, and J. Eagles. 1999. Variations in lipophilic and polar flavonoids in the genus Tanacetum. Phytochemistry 52:1301-1306. 